\title{
Serum coiled-coil domain containing 25 protein as a potential screening/diagnostic biomarker for cholangiocarcinoma
}

\author{
RAVINNIPA CHANAKANKUN ${ }^{1}$, TANAKORN PROUNGVITAYA ${ }^{1}$, DARAPORN CHUA-ON ${ }^{1}$, \\ TEMDUANG LIMPAIBOON $^{1,2}$, SITTIRUK ROYTRAKUL ${ }^{3}$, APINYA JUSAKUL ${ }^{1,2}$, ATTAPOL TITAPUN ${ }^{4}$, \\ APIWAT JAREARNRAT ${ }^{4}$ and SIRIPORN PROUNGVITAYA ${ }^{1,2}$ \\ ${ }^{1}$ Centre of Research and Development of Medical Diagnostic Laboratories, Faculty of Associated Medical Sciences; \\ ${ }^{2}$ Cholangiocarcinoma Research Institute, Faculty of Medicine, Khon Kaen University, Muang, Khon Kaen 40002; \\ ${ }^{3}$ National Center for Genetic Engineering and Biotechnology, National Science and Technology Development Agency, \\ Khlong Luang, Pathumthani 12120; ${ }^{4}$ Department of Surgery, Faculty of Medicine, Khon Kaen University, \\ Muang, Khon Kaen 40002, Thailand
}

Received January 3, 2019; Accepted October 16, 2019

DOI: $10.3892 / 01.2019 .11162$

\begin{abstract}
Coiled-coil domain containing 25 (CCDC25) was previously reported to be upregulated in cholangiocarcinoma (CCA) tissues compared with adjacent normal tissues. The present study investigated whether serum CCDC25 level may be used as a potential marker for the diagnosis of CCA. Bioinformatics tools were used to reveal that CCDC25 is secreted into plasma/serum via a non-conventional pathway, which secretes proteins independently from the endoplasmic reticulum/golgi complex, but is yet to be fully elucidated. Subsequently, the CCDC25 levels in the sera of patients with CCA $(n=141)$, patients with benign biliary disease (BBD; $\mathrm{n}=53$ ) and healthy controls $(\mathrm{HC} ; \mathrm{n}=72)$ were measured using a quantitative dot blot assay based on the standard curve created using recombinant $\mathrm{CCDC} 25$ protein. The results demonstrated that the serum CCDC25 level in the CCA group $(0.28 \pm 0.06 \mathrm{ng} / \mu \mathrm{l})$ was significantly higher compared with that in the BBD $(0.15 \pm 0.03 \mathrm{ng} / \mu \mathrm{l})$ or $\mathrm{HC}(0.0017 \pm 0.0008 \mathrm{ng} / \mu \mathrm{l})$ groups. Serum CCDC25 level provided an improved resolution $(\mathrm{P}=0.0001)$ compared with carcinoembryonic antigen $(\mathrm{P}=0.098)$ or carbohydrate antigen $19-9(\mathrm{P}=0.271)$ for the differential diagnosis between BBD and CCA. Receiver operating characteristic curve analysis revealed high sensitivity and specificity of serum CCDC25 level to differentiate between patients with CCA and HC (93.0 and 100\%, respectively), and also to differentiate between patients with CCA and patients
\end{abstract}

Correspondence to: Dr Siriporn Proungvitaya, Centre of Research and Development of Medical Diagnostic Laboratories, Faculty of Associated Medical Sciences, Khon Kaen University, 123 Mittapap Road, Muang, Khon Kaen 40002, Thailand

E-mail: sirpat@kku.ac.th

Key words: cholangiocarcinoma, coiled-coil domain containing 25, serum, screening, diagnosis with BBD (75.0 and 84.0\%, respectively). CCDC25 expression was further investigated in $23 \mathrm{CCA}$ tissues, and CCDC25 expression in cancer tissues was moderately correlated with the serum CCDC25 level $\left(\mathrm{r}^{2}=0.52, \mathrm{P}=0.01\right)$. Among patients with CCA, serum CCDC25 level was significantly higher in patients with non-metastatic CCA compared with patients with metastatic CCA. Correspondingly, a higher serum CCDC25 level was associated with a longer overall survival time in patients with CCA. In conclusion, serum CCDC25 level may be a promising screening and diagnostic marker for the differential diagnosis of CCA.

\section{Introduction}

Cholangiocarcinoma (CCA), a malignancy that arises from cholangiocytes, is highly endemic in Southeast Asia, particularly in northeastern Thailand (1). Chronic biliary tract inflammation due to liver fluke [Opisthorchis viverrini (OV)] infection together with exposure to carcinogens associated with poor hygiene is the most common risk factor for CCA in the endemic areas (1). At present, the prognosis of patients with CCA is generally poor due to lack of early detection (2). Accurate surveillance guidelines (used to detect the presence of CCA) for healthy individuals or patients with benign biliary diseases are yet to be determined (2). Imaging techniques, such as magnetic resonance imaging (MRI), magnetic resonance cholangiopancreatography and ultrasonography, may aid the early detection of CCA; however, these modalities are expensive and/or invasive (3). Serum carbohydrate antigen 19-9 (CA19-9) level is recommended as a diagnostic tumor marker but is reported to be insufficient to diagnose CCA $(3,4)$. Other tumor biomarkers, including carcinoembryonic antigen (CEA), mucin 5AC (5) and matrix metalloproteinase 7 (6), have a limited diagnostic sensitivity and/or specificity, in particular, due to upregulation of these biomarkers in benign biliary disease (BBD) (7). Therefore, the identification and establishment of a reliable biomarker for the differential diagnosis of CCA is required to improve the prognosis of patients with $\mathrm{CCA}$. 
Coiled-coil domain containing 25 (CCDC25) is widely expressed in mammalian cells. The gene encoding CCDC25 is located on chromosome $8 \mathrm{p} 21.1$, and the protein produced is 208 amino acids in length (molecular weight, $\sim 25 \mathrm{kDa}$ ) (8). CCDC25 is found in the cytoplasm of numerous cells, including hepatocytes and muscle cells (8). CCDC25 has not been detected in healthy bile duct epithelial cells, and its function under physiological conditions remains unknown (9).

A recent study revealed that CCDC25 could be detected in CCA tissues but not in adjacent normal tissues, and that migration of CCA cells is activated by bile acids, especially cholic acid, in association with upregulation of CCDC25 (10). However, whether CCDC25 is upregulated and released in the sera of patients with CCA remains unknown. The present study investigated CCDC25 expression in the sera of patients with CCA and BBD as well as healthy controls (HC). Subsequently, the diagnostic value of serum CCDC25 level was compared with that of CEA and CA19-9. In addition, the correlation between CCDC25 levels in serum and in CCA tissues was determined. The associations between serum CCDC25 levels and the clinical parameters of patients with CCA were also examined. The results demonstrated that CCDC25 was upregulated in the sera of patients with CCA, and serum CCDC25 level provided an improved resolution between patients with BBD and CCA, compared with CEA and CA19-9 biomarkers. Furthermore, the applicability of serum CCDC25 level for the differential diagnosis of CCA and its role in CCA are discussed.

\section{Materials and methods}

Ethics statement. The present study was approved by the Human Ethics Committee of Khon Kaen University (approval no. HE611410) and written informed consent was obtained from each of the participants.

Serum samples and sample size calculation. In the preliminary study, $40 \mathrm{CCA}, 20 \mathrm{BBD}$ and $20 \mathrm{HC}$ sera were used to determine the median and quartile deviation of CCDC25 relative intensity using a dot blot assay. The required number of serum samples required to compare the mean/median between two groups was calculated using the results obtained in the preliminary study and the equation described by Suresh et al (11) as follows: $\mathrm{n}=\left[(\mathrm{r}+1) \sigma^{2}\left(\mathrm{Z}_{\alpha / 2}+\mathrm{Z}_{\beta}\right)^{2}\right] / \mathrm{rd}^{2}$, where $\mathrm{n}=$ the sample size in each of the group; $\sigma=$ the estimated variance of dot blot relative intensity (standard deviation, SD); $r=$ the ratio of sample size required for two groups (generally this is 1 ); $\mathrm{d}^{2}=$ difference of dot blot relative intensity mean between two groups $=\left(\mu_{1}-\mu_{2}\right)^{2}$; $\mu_{1}=$ dot blot relative intensity mean in the CCA group; $\mu_{2}=\mathrm{dot}$ blot relative intensity mean in the $\mathrm{HC}$ group or BBD group; $\alpha=$ probability of type I error (2-sided) $=0.05 ; Z_{0.025}=1.96$; and $\beta=$ probability of type II error $=0.2, \mathrm{Z}_{0.2}=0.84$.

Bioinformatics software used for secretory protein prediction. In the present study, three bioinformatics software programs were used for the prediction of the secretory protein nature of CCDC25: i) signalP software (version 5.0; Department of Bio and Health Informatics, Technical University of Denmark) which predicts signal peptide cleavage sites in amino acid sequences using a D-score $>0.45$ (12); ii) SecretomeP software (version 2.0; Department of Bio and Health informatics, Technical University of Denmark), which predicts a non-classical secretory protein, which is any protein with a Neural Network (NN) score $>0.5$ (13); and iii) the Plasma Proteome Database (PPD 2014; Human Proteome Organization; http://plasmaproteomedatabase.org/index.html), which is one of the largest resources on plasma proteins (14), analyzed on 29th August, 2018. Moreover, Swiss Institute of Bioinformatics and NNF Center for Protein Research (STITCH; v. 5.0; http://stitch.embl.de/) was used to analyze the potential interactions of CCDC25 with other molecules. The output page showed 'list names' followed by the confidence score and proteins with a confidence score $\geq 0.4$ were selected for further analysis. Stronger associations were presented as thicker lines. Protein-protein interactions were presented as solid lines, chemical-protein interactions were presented as dashed lines and chemical-chemical interactions as dotted lines. Interactions with a protein interaction score $>0.7$ (according to STITCH) were considered high confidence interactions (15).

Sera from patients with CCA, patients with $B B D$ and $H C$. The ratio of male: female patients in the $\mathrm{HC}, \mathrm{BBD}$ and CCA groups was 21:51, 40:13 and 96:45, respectively. The CCA, BBD and HC serum samples were obtained from the Clinical Laboratory of Srinagarind Hospital (Khon Kaen, Thailand). A total of 141 serum samples from patients with CCA (median age \pm quartile deviation, $60 \pm 6.5$ years; range, 31-80 years) and 53 samples from patients with BBD (median age \pm quartile deviation, $60 \pm 8.5$ years; range, $40-76$ years), including 17 patients with chronic cholecystitis, 20 patients with chronic cholangitis and 16 patients with chronic biliary inflammation who were diagnosed by biopsy, were collected from the Cholangiocarcinoma Research Institute (CARI), Faculty of Medicine, Khon Kaen University (Khon Kaen, Thailand) between December 2014 and September 2017. Clinical laboratory data, including serum CEA and CA19-9 levels, as well as clinical data were obtained from the patient records database of the CARI. All patients with CCA in the present study had stage 3-4 intrahepatic Ov-associated CCA. Serum CA19-9 and CEA levels in the sera of patients with CCA were determined by ELISA on a Roche cobas e 801 module (cat. no. Elecsys CEA Ass; cat. no. 04491777190 and Elecsys CA19-9; cat. no. 11776193122; Roche diagnostics) in the clinical diagnostic laboratory of Srinagarind Hospital, Khon Kaen University, as previously described (16). In addition, $72 \mathrm{HC}$ serum samples (median age \pm quartile deviation, $44 \pm 15$ years; range, 19-85) were recruited from the annual health check-up of individuals between 13 and 28th September 2018 at the Faculty of Associated Medical Science AMS-KKU Excellence Laboratory), Khon Kaen University. Among the $\mathrm{HCs}$, those with abnormal liver function tests were excluded. All serum samples were kept at $-20^{\circ} \mathrm{C}$ until use.

Dot blot assay and data acquisition. A nitrocellulose membrane (GE Healthcare) was soaked in 1X Tris-buffer saline with $0.1 \%$ Tween-20 (1X TBST) for $10 \mathrm{~min}$ (room temperature) prior to setting on the Bio-Dot Microfiltration Apparatus (Bio-Rad Laboratories, Inc.). The pooled CCA sera were used as a positive control for the normalization 
of the intensity of CCA, BBD and HC serum samples. The relative intensity of each sample spot was calculated by comparison with that of the positive control as preivously described $(17,18)$. Each serum sample was diluted to $1: 3$ with normal saline and $2 \mu \mathrm{l}$ of each sample was spotted onto the membrane using a Bio-Dot Microfiltration Apparatus (Bio-Rad Laboratories, Inc.). The membrane was soaked in $5 \%$ skimmed milk in $1 \mathrm{X}$ TBST for $1 \mathrm{~h}$ at room temperature to prevent non-specific binding. The membrane was then incubated with a rabbit polyclonal primary antibody against human CCDC25 (1:500; cat. no. orb2517; Biorbyt Ltd.) overnight at $4^{\circ} \mathrm{C}$. The membrane was washed with $1 \mathrm{X}$ TBST and then incubated with a horseradish peroxidase-conjugated goat anti-rabbit IgG secondary antibody (1:10,000; cat. no. 31460; Invitrogen; Thermo Fisher Scientific, Inc.) for $1 \mathrm{~h}$ at room temperature, followed by washing with $1 \mathrm{X}$ TBST. The chemiluminescent signal was detected using an Enhanced Chemiluminescence plus reagent (GE Healthcare) and quantified on an Amersham imager 600 (GE Healthcare). The CCDC25 concentration in each serum sample was calculated based on the standard curve prepared using the standard recombinant CCDC25 protein (cat. no. orb424527; Biorbyt Ltd.). The original stock of known concentration $(1 \mu \mathrm{g} / \mu \mathrm{l})$ was diluted to $1 \mathrm{ng} / \mu 1$, followed by the preparation of serial dilutions of $1,0.5,0.25$, $0.125,0.0625,0.0313,0.0156$ and $0.0078 \mathrm{ng} / \mu \mathrm{l}$ (Fig. 1). Dot blot results were normalized using positive controls (pooled CCA serum samples) with ImageJ software (version $1.52 \mathrm{~d}$; National Institutes of Health).

Paraffin-embedded CCA tissue samples. A total of 23 pairs of adjacent non-cancerous and cancerous tissue samples were obtained from 23 patients with CCA that were diagnosed by a biopsy procedure at the Cholangiocarcinoma Research Institute, Faculty of Medicine, Khon Kaen University between June 2015 and March 2017. The 23 patients included seven patients with non-metastatic CCA [high serum CCDC25 level $(>0.2 \mathrm{ng} / \mu \mathrm{l})$ and a long survival time ( $>377$ days)] and 16 patients with metastatic CCA [high serum CCDC25 level but lower than median value of serum CCDC25 level in non-metastatic CCA and a short survival time ( $<377$ days)]. The CCA tissues were paraffin-embedded and sectioned, placed on slides coated with commercial acetone mixed with 3-Aminopropyl triethoxysilane and deionized water, and stored at room temperature. The CCA sections were used to validate CCDC25 expression in sera obtained from patients with CCA. The present study used as many paraffin-embedded CCA sections that could be included according to the following inclusion criteria: i) CCA tissues had matched CCA serum samples for IHC analysis; ii) The CCD25 concentration was higher than cut-off value in serum; iii) The status of tissues from non-metastatic patients with CCA was alive and patients with metastatic CCA; and iv) Survival time was higher than median for non-metastatic CCA, and lower than the median for metastatic CCA (median, 377 days).

Immunohistochemistry. The 23 paraffin-embedded CCA tissue sections were heat-fixed at $60^{\circ} \mathrm{C}$ in a hot air oven for $30 \mathrm{~min}$. The sections were then deparaffinized by soaking in xylene three times for 5 min each, rehydrated by soaking in absolute ethanol and 95\% ethanol twice for 2 min each, followed by $70 \%$ ethanol for $2 \mathrm{~min}$. Antigen retrieval was performed by boiling the sections in $0.01 \mathrm{M}$ citrate buffer pH6.0 (Abcam) for $10 \mathrm{~min}$, followed by incubation at room temperature for $10 \mathrm{~min}$ and washing in $1 \mathrm{X}$ PBS for $5 \mathrm{~min}$. Subsequently, endogenous peroxidase activity was blocked with $3 \% \mathrm{H}_{2} \mathrm{O}_{2}$ in methanol for $1 \mathrm{~h}$ (room temperature) in the dark and non-specific binding was blocked with $20 \%$ fetal bovine serum (Gibco; Thermo Fisher Scientific, Inc.) for $2 \mathrm{~h}$ at room temperature. The sections were then incubated with $200 \mu \mathrm{l}$ rabbit anti-CCDC25 polyclonal antibody (1:400; cat. no. orb2517; Biorbyt Ltd.) overnight at $4^{\circ} \mathrm{C}$. The sections were washed twice with $1 \mathrm{X}$ PBS-T for $10 \mathrm{~min}$ each then incubated with $200 \mu 1$ anti-rabbit Ig antibody (commercial Dako EnVision+ System- HRP Labelled Polymer Anti-Rabbit; Code K4003; cat. no. LOT 10147964) (Dako; Agilent Technologies, Inc.) for $1 \mathrm{~h}$. The signal was then developed by incubation with 3,3'-diaminobenzidine (Dako; Agilent Technologies, Inc.) for $5 \mathrm{~min}$ in the dark at room temperature. The sections were washed with running water for $5 \mathrm{~min}$ and counterstained with hematoxylin for $5 \mathrm{~min}$ at room temperature. The sections were then dehydrated by soaking for 2 min each in 70\% ethanol, 95\% ethanol, absolute ethanol and for $5 \mathrm{~min}$ in xylene. Finally, the sections were mounted with Permount ${ }^{\mathrm{TM}}$ (Thermo Fisher scientific, Inc.) and sealed with a cover glass. A light microscope was used for staining visualization.

The staining was assessed using the H-score method, recording both the intensity of staining $(0=$ no staining; $1+=$ weak staining; $2+=$ moderate staining; and $3+=$ strong staining) and the percentage of stained tumor cells, which results in an $\mathrm{H}$-score between 0 and 300 for each sample (19). Immunohistochemistry results were obtained from ten fields per sample and averaged to decrease the variation in detection (magnification, $\mathrm{x} 400$ ). The $\mathrm{H}$-score was calculated as a sum of the intensity as follows (19): $\mathrm{H}$-score $=(\%$ of positively stained tumor cells at weak intensity $\times 1)+(\%$ of positively stained tumor cells at moderate intensity $\times 2)+(\%$ of positively stained tumor cells at strong intensity $\mathrm{x} 3$ ).

Statistical analysis. The data are presented as the median \pm quartile deviation and the range (minimum to maximum). Comparisons among two independent, two dependent and three groups were performed using a Mann-Whitney U test, a paired Student's t-test and a Kruskal-Wallis test (and Dunn-Bonferroni post-hoc anlaysis), respectively. The associations and correlations between the clinical data of patients and the serum CCDC25 level were analyzed using the $\chi^{2}$ test and Spearman's correlation test, respectively. The Mann-Whitney U test was used to compare low and high serum CCDC25 levels. Kaplan-Meier analysis was used to estimate the overall survival time, and the Log-rank test was used to compare differences in the curves. In addition, a receiver operating characteristic (ROC) curve was used to determine the cut-off values to obtain the highest sensitivity and specificity values. GraphPad Prism software (version 5; GraphPad Software Inc.) and SPSS software (version 16; SPSS, Inc.) were used for statistical analyses. $\mathrm{P}<0.05$ was considered to indicate a statistically significant difference. 
A

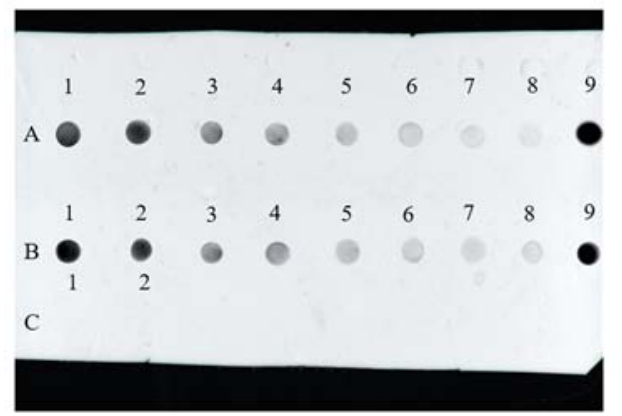

B

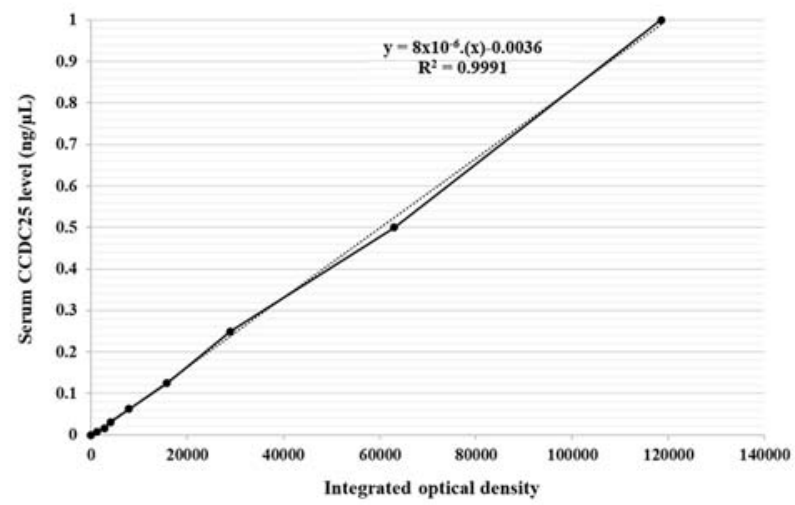

Figure 1. CCDC25 serum levels were detected using the dot blot assay. (A) Representative dot blot assay to detect CCDC25 serum levels. Samples A1 and B1 were the standard $(1 \mathrm{ng} / \mu \mathrm{l})$, samples A2-A8 and B2-B8 were duplicates of two-fold serial dilutions $(0.5,0.25,0.125,0.0625,0.0313,0.0156$ and $0.0078 \mathrm{ng} / \mu \mathrm{l})$, samples A9 and B9 were the positive control (pooled CCA serum samples) and samples C1-C2 were the blank control (saline solution). (B) The standard curve of CCDC25 levels. CCDC25, coiled-coil domain containing 25.

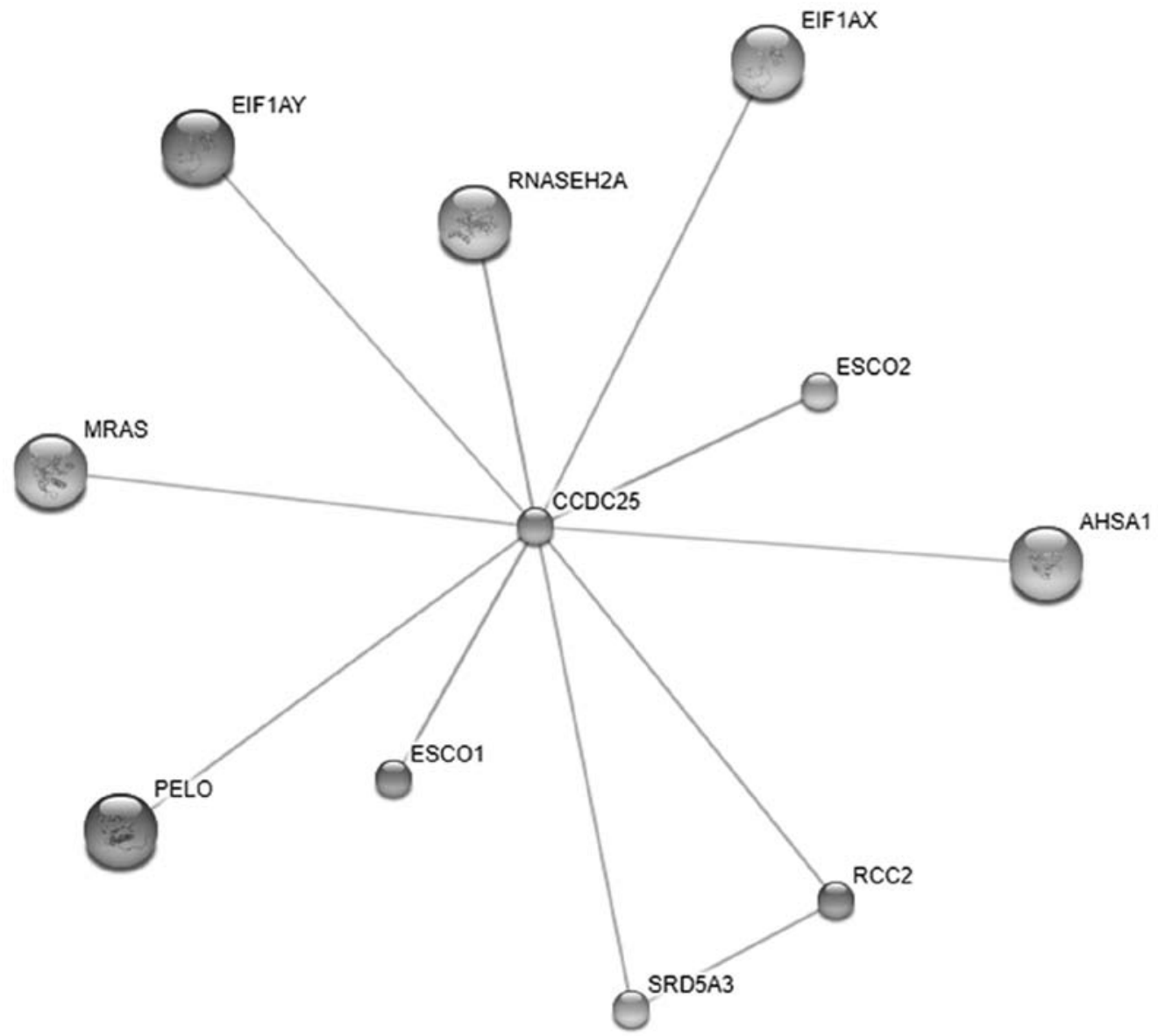

Figure 2. Protein-ligand interaction map of CCDC25-related proteins using STITCH v.5.0 software. Stronger associations are presented as thicker lines. Protein-protein interactions were indicated using solid lines, and no chemical-protein interactions or interactions between chemical and chemical molecules were observed. CCDC25, coiled-coil domain containing 25 .

\section{Results}

Bioinformatics analysis to predict the secretory protein nature of $C C D C 25$. SignalP software predicts that a protein is secretory via a conventional pathway if the D-score is $>0.45(12)$. However, CCDC25 was found to have a D-score of 0.18 , suggesting that CCDC25 is not secreted via a conventional endoplasmic reticulum (ER)-Golgi pathway. SecretomeP software predicts that a protein is secreted via a non-conventional route if the $\mathrm{NN}$ score is $>0.5$. CCDC25 was found to have an $\mathrm{NN}$ score of 0.77 . In addition, CCDC25 is listed as a plasma protein in the PPD (20). Moreover, STITCH software showed 
Table I. Demographic and clinical characteristics of the study cohort.

\begin{tabular}{lcccc}
\hline Parameter (normal range) & HC, $\mathrm{n}=72$ & BBD, $\mathrm{n}=53$ & CCA, $=141$ & P-value \\
\hline Age & $44 \pm 15(19-85)$ & $60 \pm 8.5^{\mathrm{a}}(40-76)$ & $60 \pm 6.5^{\mathrm{c}}(31-80)$ & $<0.001^{* * *}$ \\
Total protein $(6.5-8.8 \mathrm{~g} / \mathrm{dl})$ & NA & $7.3 \pm 0.4^{\mathrm{b}}(5.9-8.7)$ & $7.45 \pm 0.5^{\mathrm{d}}(4.6-10.0)$ & 0.283 \\
Total bilirubin $(0.25-1.5 \mathrm{mg} / \mathrm{dl})$ & NA & $0.8 \pm 1.2^{\mathrm{b}}(0.2-31.7)$ & $0.6 \pm 0.8^{\mathrm{d}}(0.2-24.9)$ & 0.219 \\
Direct bilirubin $(0-0.5 \mathrm{mg} / \mathrm{dl})$ & $\mathrm{NA}$ & $0.4 \pm 1.1^{\mathrm{b}}(0-24.3)$ & $0.3 \pm 0.6^{\mathrm{d}}(0-13.7)$ & 0.073 \\
ALT $(4-36 \mathrm{U} / \mathrm{l})$ & $25 \pm 6(7-85)$ & $44 \pm 24.5^{\mathrm{b}}(1-795)$ & $38 \pm 21^{\mathrm{d}}(1-795)$ & $<0.001^{* * * *}$ \\
AST $(12-32 \mathrm{U} / \mathrm{l})$ & $21.5 \pm 5.4(6-62)$ & $39 \pm 27.7^{\mathrm{b}}(15-523)$ & $38 \pm 19^{\mathrm{d}}(4-1,112)$ & $<0.001^{* * * *}$ \\
ALP $(42-121 \mathrm{U} / \mathrm{l})$ & $50 \pm 8.2(1-98)$ & $186 \pm 87.7^{\mathrm{b}}(75-719)$ & $165.5 \pm 78.5^{\mathrm{d}}(35-1,068)$ & $<0.001^{* * * *}$ \\
CA19-9 $(0-37 \mathrm{U} / \mathrm{ml})$ & NA & $53.4 \pm 26.3^{\mathrm{e}}(0.6-87.6)$ & $73.5 \pm 29.8^{\mathrm{f}}(1.6-119.7)$ & 0.271 \\
CEA $(0-5 \mathrm{ng} / \mathrm{ml})$ & NA & $3.9 \pm 2.6^{\mathrm{g}}(0.6 \pm 13.8)$ & $5.7 \pm 5.1^{\mathrm{h}}(0.9-28.9)$ & 0.098 \\
Survival time (days) & NA & $1,871 \pm 140(137-3,025)$ & $456 \pm 59^{\mathrm{d}}(139-2,277)$ & $0.02^{* * *}$ \\
\hline
\end{tabular}

a,b,c,d,e,f,g,h represent the number of samples analyzed, 51, 47, 141, 138, 46, 125, 40 and 112, respectively. *Significant difference between HC and CCA; ${ }^{* *}$ Significant difference between HC and BBD; ${ }^{* * *}$ Significant difference between BBD and CCA. HC, healthy control; BBD, benign biliary disease; CCA, cholangiocarcinoma; NA, not available; ALT, alanine transaminase; AST, aspartate transaminase; ALP, alkaline phosphatase. CA19-9, carbohydrate antigen 19-9; CEA, carcinoembryonic antigen. Data are presented as the median \pm quartile deviation (minimum, maximum).

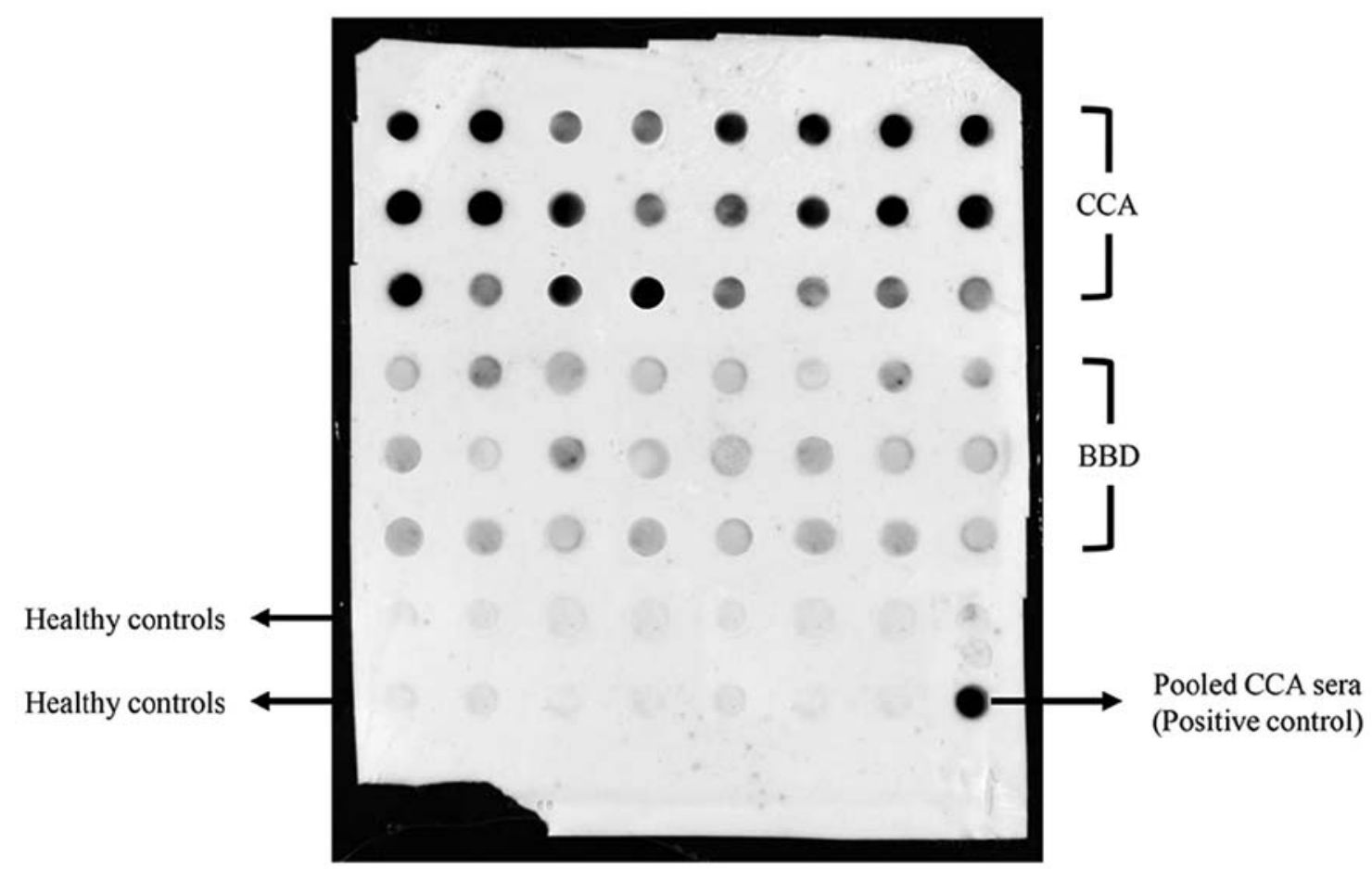

Figure 3. Representative dot blot images from the Amersham imager600 analyzer. The spots were presented in order along the horizontal lines. A spot at the right lower corner was a positive control (pooled CCA sera). The first three lines were CCA sera, the next three lines were BBD serum samples and the last two lines were healthy control serum samples. CCA, cholangiocarcinoma; BBD, benign biliary disease.

the interactions between CCDC25 and muscle RAS oncogene homolog, eukaryotic translation initiation factor 1A, Y-linked (EIF1AY), eukaryotic translation initiation factor 1A, X-linked, ribonuclease $\mathrm{H} 2$, subunit $\mathrm{A}$; catalytic subunit of RNase HII, establishment of cohesion 1 homolog 1/2 (ESCO1/2), establishment of cohesion 1 homolog 2 (ESCO2), activator of heat shock $90 \mathrm{kDa}$ protein ATPase homolog 1, regulator of chromosome condensation 2 (RCC2), steroid $5 \alpha$-reductase 3 and pelota homolog all had a confidence score $>0.4$ (Fig. 2).
Serum CCDC25 levels in the CCA, BBD and HC groups. The preliminary results demonstrated that the median and quartile deviation of CCDC25 relative intensity in CCA, $\mathrm{BBD}$ and $\mathrm{HC}$ sera were $0.95 \pm 1.25,0.48 \pm 1.03$ and $0.03 \pm 0.07$, respectively. Thus, according to the aforementioned equation, the minimum sample size necessary for comparison of the median between the CCA and HC group was 8 , and the minimum sample size necessary for the comparison between the CCA and BBD groups was 92. A representative dot blot 
image of CCDC25 levels in serum samples is presented in Fig. 3. The demographic and clinical data of the participants are summarized in Table I. CCDC25 levels in the sera of 141 patients with CCA, 53 patients with BBD and $72 \mathrm{HC}$ were measured using dot blot analysis based on a CCDC25 standard curve (Fig. 1). As presented in Fig. 4A, the median CCDC25 level in the sera of patients with CCA was significantly higher compared with that of patients with BBD or HC. As presented in Fig. 4A, CCDC25 levels of patients with CCA appeared to be divided into high and low groups. Therefore, the distribution pattern of patients with CCA was investigated based on their serum CCDC25 levels (Fig. 5). From this distribution pattern, a difference was identified between the low $(n=29)$ and high $(n=112)$ CCDC25 groups at concentrations of 0.185 and $0.215 \mathrm{ng} / \mu 1$. Accordingly, a cut-off value of $0.2 \mathrm{ng} / \mu 1$ was set to classify the low and high CCDC25 groups. The results demonstrated that 112 of 141 CCA cases were in the high CCDC25 group, whereas only three of $53 \mathrm{BBD}$ cases were in the high CCDC25 group (Fig. 4A).

Evaluation of serum CCDC25 level for the diagnosis of CCA. The data in Fig. 4A revealed that serum CCDC25 level was a good biomarker to discriminate between BBD and CCA. The diagnostic capability of CCDC25 was further compared with that of CEA and CA19-9. As presented in Fig. 4B and C, the serum CEA and CA19-9 levels were not significantly different between the BBD and CCA groups; however, both markers tended to be higher in the CCA group compared with the BBD group. When correlation analyses were performed between serum CCDC25 level and CEA or CA19-9 levels, no correlation was observed, as presented in Fig. 6A and B. This suggested that CCDC25 may serve as an independent biomarker in CCA.

To elucidate further whether serum CCDC25 level can be used to diagnose $\mathrm{CCA}$, ROC curve analysis was performed for the CCA, BBD and HC groups (Figs. 7 and 8A; Table II) Between the CCA and $\mathrm{HC}$ groups, the sensitivity and specificity of the serum CCDC25 levels were 93.0 and 100\%, respectively, with a cut-off value of $0.11 \mathrm{ng} / \mu \mathrm{l}(\mathrm{P}<0.0001)$. Between the BBD and HC groups, the sensitivity and specificity were 98.1 and $90.4 \%$, respectively, with a cut-off value of $0.045 \mathrm{ng} / \mu 1$ $(\mathrm{P}<0.0001)$. Between the BBD and CCA groups, the sensitivity and specificity were 75.0 and $84.0 \%$, respectively $(\mathrm{P}<0.0001)$. In contrast to $\mathrm{CCDC} 25$, serum CA19-9 level between the BBD and CCA groups provided a sensitivity and specificity of 52.4 and $46.5 \%$, respectively, with an area under the curve of 0.483 at a cut-off value of $105.4 \mathrm{U} / \mathrm{ml}(\mathrm{P}=0.072)$. Similarly, the CEA level between the BBD and CCA groups provided a sensitivity and specificity of 54.4 and $60 \%$, respectively, with an area under the curve of 0.558 at a cut-off value of $19.6 \mathrm{ng} / \mathrm{ml}$ $(\mathrm{P}=0.274$; Fig. 8B and $\mathrm{C})$.

Correlation between CCDC25 expression in serum and CCA tissues. As presented in Fig. 4A, serum CCDC25 levels were notably low in the $\mathrm{HC}$ group and were markedly high in patients with CCA. Thus, it was assumed that serum CCDC25 is predominantly produced and released from CCA cells. To test this hypothesis, 23 paraffin-embedded CCA tissues were selected from the 141 patients with CCA whose sera were
$\mathbf{A}$
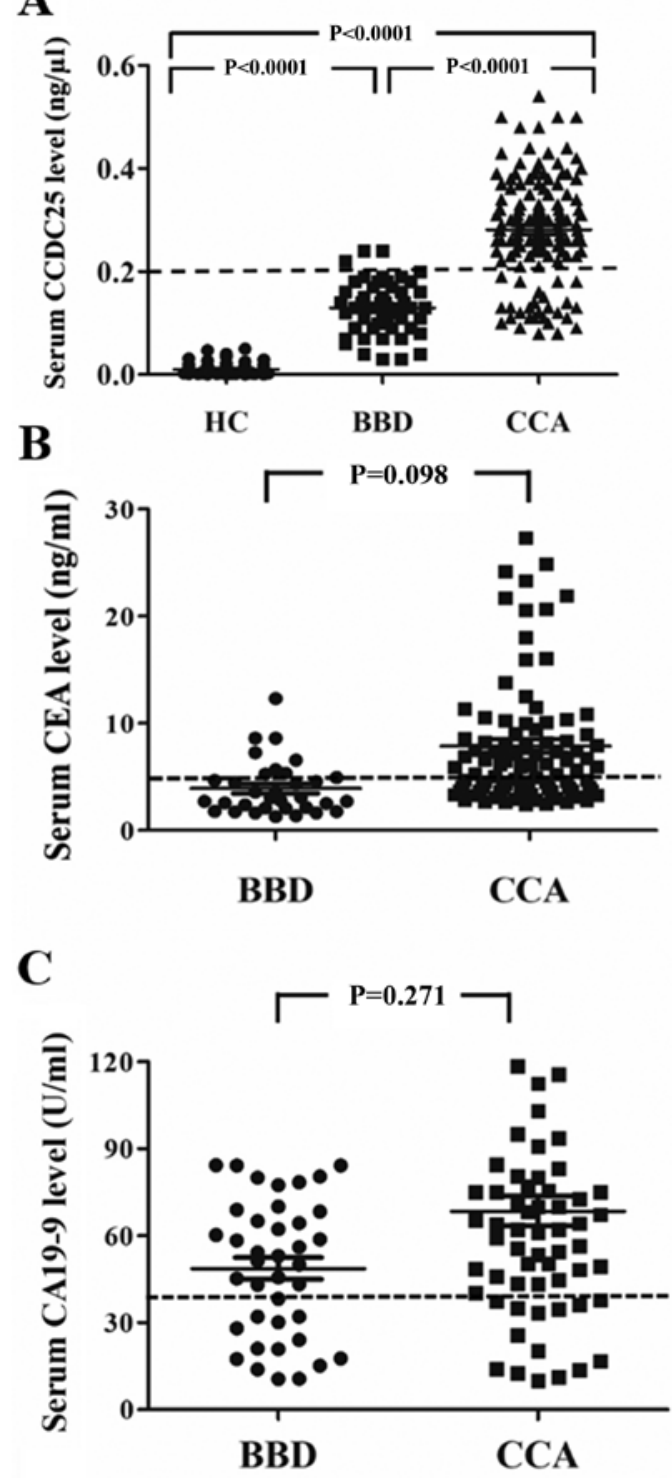

Figure 4. Serum CCDC25, CA19-9 and CEA levels in the CCA, BBD and HC groups. (A) The median level \pm quartile deviation of the CCDC25 level was $0.0017 \pm 0.0008 \mathrm{ng} / \mu 1$ in the $\mathrm{HC}$ group, $0.15 \pm 0.03 \mathrm{ng} / \mu 1$ in the BBD group and $0.28 \pm 0.06 \mathrm{ng} / \mu \mathrm{l}$ in the CCA group. The serum CCDC25 level at $0.2 \mathrm{ng} / \mu \mathrm{l}$ was used as the cut-off value to distinguish between patients with CCA with low and high serum CCDC25 level. (B) Median level \pm quartile deviation of the CEA level was $3.9 \pm 2.6 \mathrm{ng} / \mathrm{ml}$ in the BBD group and $5.7 \pm 5.1 \mathrm{ng} / \mathrm{ml}$ in CCA group and the cut-off level was $5 \mathrm{ng} / \mathrm{ml}$. (C) The median level \pm quartile deviation of the CA19-9 level was $53.4 \pm 26.3 \mathrm{U} / \mathrm{ml}$ in the BBD group and $73.5 \pm 29.8 \mathrm{U} / \mathrm{ml}$ in the CCA group and the cut-off level was $37 \mathrm{U} / \mathrm{ml}$. CCDC25, coiled-coil domain containing 25; CA19-9, carbohydrate antigen 19-9; CEA, carcinoembryonic antigen; CCA, cholangiocarcinoma; $\mathrm{BBD}$, benign biliary disease; HC, healthy control.

used to evaluate the CCDC25 level. CCDC25 expression in CCA tissues was demonstrated using immunohistochemical staining and the intensity of CCDC25 expression in CCA tissues was determined using the H-score system (19). Correlation between the serum CCDC25 level and CCDC25 expression in the corresponding CCA tissue was examined. The results revealed a moderate correlation $(21)\left(r^{2}=0.52\right.$, $\mathrm{P}=0.01$ ) between serum and tissue CCDC25 expression levels, suggesting that serum CCDC25 is mainly derived from CCA tissues (Fig. 9). 


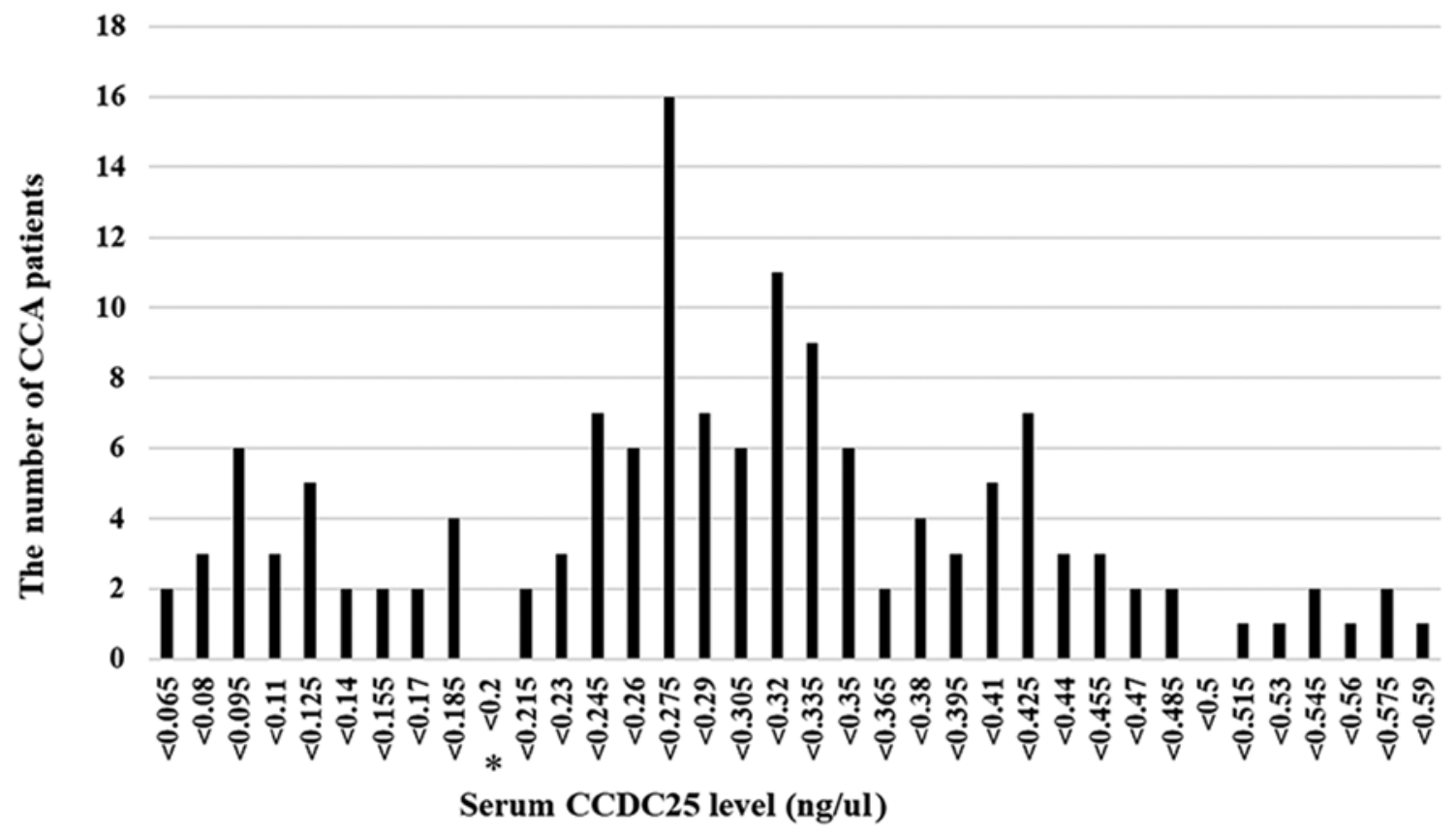

Figure 5. Distribution of the CCDC25 serum levels in patients with CCA. The frequency plot of the CCDC25 serum level in patients with CCA revealed two distinct populations, which were separated at concentration $0.2 \mathrm{ng} / \mu 1$. Therefore, $0.2 \mathrm{ng} / \mu 1$ was used as the cut-off value to distinguish between low and high CCDC25 levels in serum samples obtained from patients with CCA. CCDC25, coiled-coil domain containing 25; CCA, cholangiocarcinoma.

A

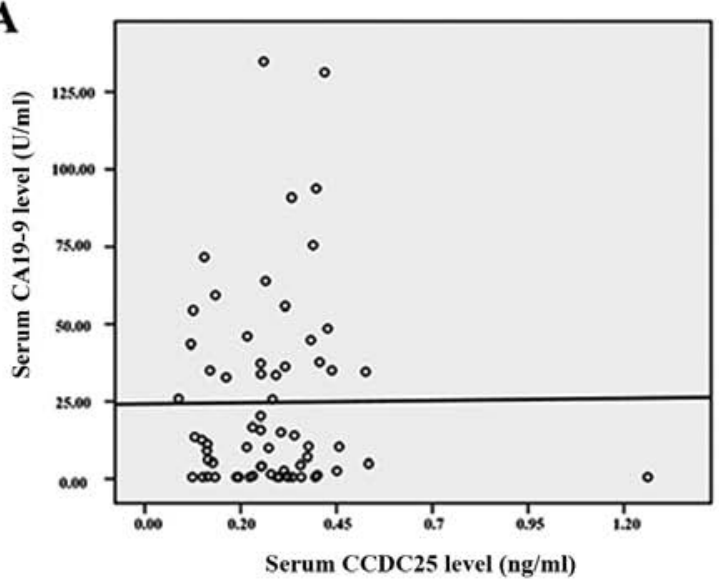

B

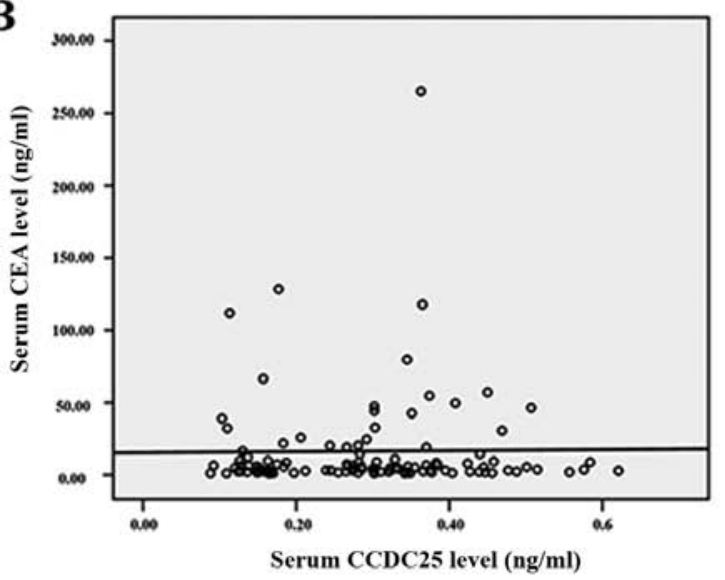

Figure 6. Correlation between CCDC25 serum levels and CA19-9 and CEA serum levels. (A) Correlation between CCDC25 serum level and CA19-9 serum level $(\mathrm{r}=0.04 ; \mathrm{P}=0.81)$ and $(\mathrm{B}) \mathrm{CEA}$ serum level $(\mathrm{r}=0.03 ; \mathrm{P}=0.62)$, calculated using the Spearman's correlation test, both exhibited a negligible positive correlation. CCDC25, coiled-coil domain containing 25; CA19-9, carbohydrate 19-9 antigen; CEA, carcinoembryonic antigen.

Associations of serum CCDC25 levels with clinical parameters. To identify the possible clinical importance of CCDC25, the associations between serum CCDC25 levels and clinical parameters were examined. For this purpose, CCA patients were divided into high serum CCDC25 and low serum CCDC25 groups, and the distribution patterns of each clinical parameter in both groups were analyzed (Table III). The results demonstrated that a high serum CCDC25 level was associated with patients with non-metastatic CCA. The median survival time was longer for the high serum CCDC25 group compared with the low serum CCDC25 group. Similarly, Kaplan-Meier analysis revealed that the overall survival time of patients with CCA with high serum CCDC25 level was significantly longer compared with that of patients with CCA with low CCDC25 level (365 vs. 242 days; $\mathrm{P}=0.031$; Fig. 10).

\section{Discussion}

In the present study, bioinformatics analyses using SignalP, SecretomeP and PPD revealed that CCDC25 lacks a signal peptide and therefore cannot be transported via a conventional secretory pathway of the ER-Golgi system towards the plasma membrane. However, a previous study used mass spectrometry to reveal that CCDC25 was present in plasma obtained from healthy individuals (20). The present study demonstrated that, although the level was low, CCDC25 was detected in the sera of $\mathrm{HC}$, and a high expression level was 
Table II. Receiver operating charactersitic curve analysis of the diagnostic value of CCDC25, CEA and CA19-9 in CCA.

\section{$\mathrm{A}, \mathrm{CCDC} 25$}

\begin{tabular}{lcccrr}
\hline Comparison & Sensitivity $(\%)$ & Specificity $(\%)$ & AUC & Cut-off value & P-value \\
\hline CCA vs. HC & 93.0 & 100 & 0.955 & $0.110 \mathrm{ng} / \mu 1$ & $<0.0001$ \\
BBD vs. HC & 98.1 & 90.4 & 0.867 & $0.045 \mathrm{ng} / \mu 1$ & $<0.0001$ \\
CCA vs. BBD & 75.0 & 84.0 & 0.880 & $0.180 \mathrm{ng} / \mu 1$ & $<0.0001$ \\
\hline
\end{tabular}

B, CA19-9

\begin{tabular}{|c|c|c|c|c|c|}
\hline Comparison & Sensitivity (\%) & Specificity (\%) & AUC & Cut-off value & P-value \\
\hline CCA vs. BBD & 52.4 & 46.5 & 0.483 & $105.400 \mathrm{U} / \mathrm{ml}$ & 0.072 \\
\hline
\end{tabular}

C, CEA

\begin{tabular}{lccccc}
\hline Comparison & Sensitivity $(\%)$ & Specificity $(\%)$ & AUC & Cut-off value & P-value \\
\hline CCA vs. BBD & 54.4 & 60.0 & 0.558 & $19.600 \mathrm{ng} / \mathrm{ml}$ & 0.274 \\
\hline
\end{tabular}

CCDC25, coiled-coil domain containing 25; CEA, carcinoembryonic antigen; CA19-9, carbohydrate antigen 19-9; CCA, cholangiocarcinoma; AUC, area under the curve; BBD, benign biliary disease; HC, healthy control.

A

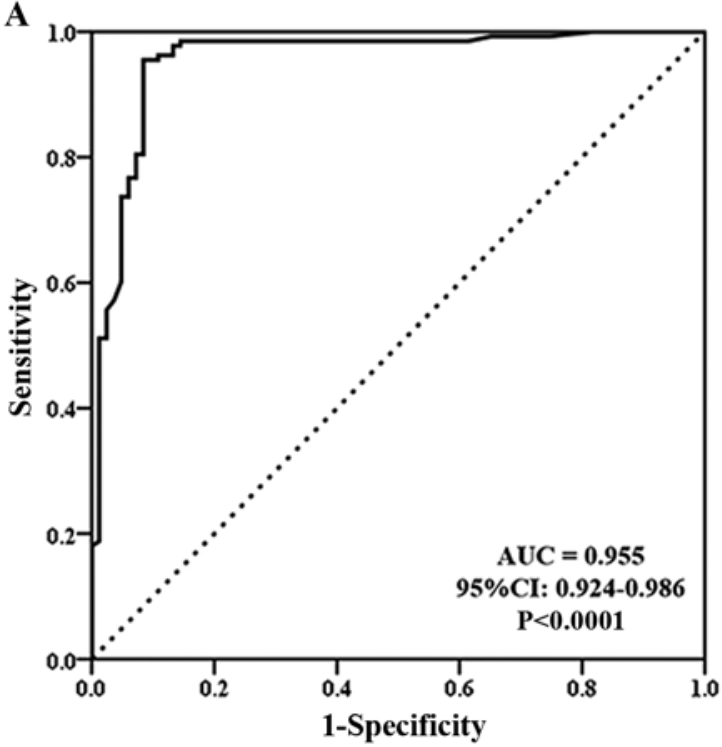

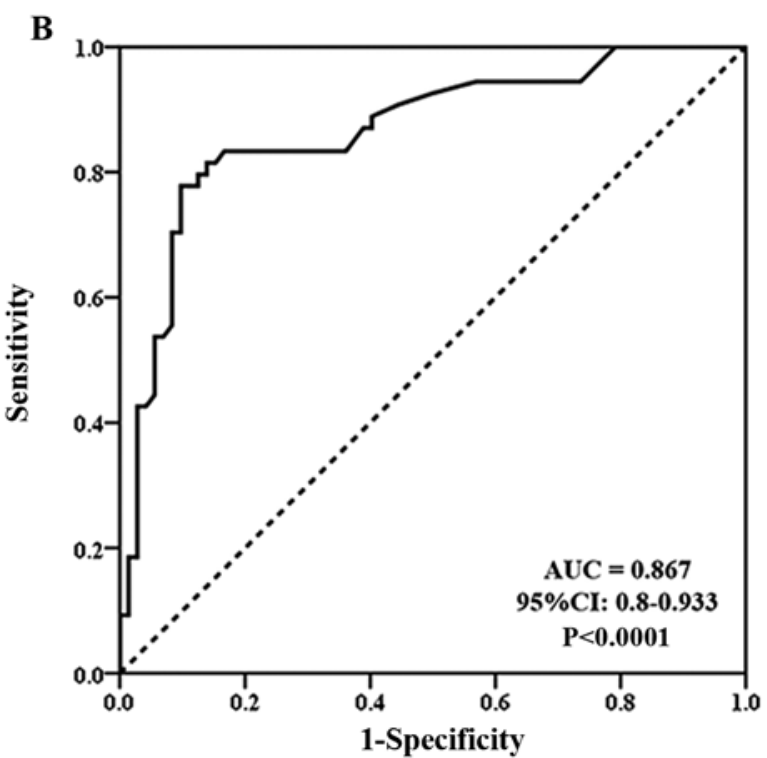

Figure 7. ROC curve evaluation of serum CCDC25 levels in the CCA, BBD and HC groups. (A) ROC curve of the CCDC25 level between the CCA and HC groups represented $93 \%$ sensitivity and $100 \%$ specificity with a cut-off CCDC25 level of $0.11 \mathrm{ng} / \mu 1$. (B) ROC curve of the CCDC25 level between the BBD and HC groups represented $98.1 \%$ sensitivity and $90.4 \%$ specificity with a cut-off CCDC 25 level of $0.045 \mathrm{ng} / \mu 1$. ROC, receiver operating characteristic; CCDC25, coiled-coil domain containing 25; CCA, cholangiocarcinoma; BBD, benign biliary disease; HC, healthy control. CCDC25, coiled-coil domain containing 25 ; AUC, area under the curve; $\mathrm{CI}$, confidence interval.

detected in the sera of the majority of patients with CCA. Thus, CCDC25 is transported to the plasma membrane via an unconventional pathway. Unconventional protein secretion is complex and comprises cargos without a signal peptide or a transmembrane domain that can translocate across the plasma membrane, and cargos that reach the plasma membrane by bypassing the Golgi apparatus despite entering the ER (22).
A previous study reported that $\mathrm{CCDC} 25$ was upregulated in CCA tissues when compared with adjacent non-CCA tissues (10). In the present study, a quantitative dot blot assay based on the standard curve created using standard CCDC25 protein was used to reveal that the serum CCDC25 level of patients with CCA was significantly higher compared with that of $\mathrm{HCs}$ and patients with BBD. Furthermore, the serum CCDC25 level could be used to differentiate between $\mathrm{BBD}$ and $\mathrm{CCA}$ 
Table III. Association of patient clinical data and low and high serum CCDC25 levels in patients with cholangiocarcinoma.

Serum CCDC25 level (ng/ $\mu 1)$

Clinicopathological parameter

Low $(<0.2)(n=37)$

$\operatorname{High}(>0.2)(\mathrm{n}=104)$

P-value

Sex, n (\%)

Male

24 (17.5)

Female

$0.30^{\mathrm{a}}$

Lymph node metastasis, n (\%)

No

Yes

$60 \pm 6.2(41,76)$

$69(50)$

$41(29.8)$

$0.008^{* a}$

Age

$8.3 \pm 0.4(5.6,9.9)$

$60 \pm 6(31,80)$

$0.978^{\mathrm{b}}$

Liver function

Total protein $(6.5-8.8 \mathrm{~g} / \mathrm{dl})$

Total bilirubin $(0.25-1.5 \mathrm{mg} / \mathrm{dl})$

$0.5 \pm 0.6(0.3,24.9)$

$9.6 \pm 0.5(4.6,10)$

$0.351^{\mathrm{b}}$

Direct bilirubin $(0-0.5 \mathrm{mg} / \mathrm{dl})$

$0.2 \pm 0.5(0.1,13.7)$

$0.6 \pm 0.7(0.2,28.2)$

$0.493^{\mathrm{b}}$

ALT (4-36 U/1)

$30 \pm 13.2(12,339)$

$0.3 \pm 0.6(0,22.9)$

$0.763^{\mathrm{b}}$

AST (12-32 U/l)

$33 \pm 11.5(14,612)$

$41 \pm 19.7(19,795)$

$0.213^{\mathrm{b}}$

ALP (42-121 U/1)

$138 \pm 108.7(63,712)$

$42 \pm 20(4,112)$

$0.222^{\mathrm{b}}$

$181 \pm 75.7(35,1,068)$

$0.173^{\mathrm{b}}$

Tumor marker

CEA (0-5 ng/ml)

$3.9 \pm 5.9(1.1,28.9)$

CA19-9 (0-37 U/ml)

$54.7 \pm 10.4(1.1,88.9)$

Survival time (days)

$242 \pm 108(17,1,907)$

$5.3 \pm 4.1(1.4,31.5)$

$0.623^{\mathrm{b}}$

$73.8 \pm 20.6(1.2,119.7)$

$0.958^{\mathrm{b}}$

$365 \pm 199(34,3,025)$

$0.03^{* b}$

Data are presented as the median \pm quartile deviation (minimum, maximum). These variables were analyzed from low and high groups of serum CCDC25 level (cut-off value at $0.2 \mathrm{ng} / \mu 1$ ). ${ }^{a}$ Value was calculated using the $\chi^{2}$ test for association of clinical data with serum CCDC25

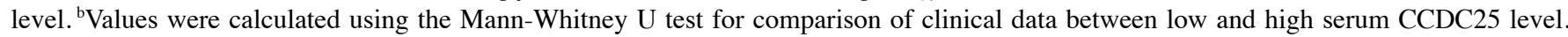
${ }^{*} \mathrm{P}<0.05$. CCDC25, coiled-coil domain containing 25; ALT, alanine transaminase; AST, aspartate transaminase; ALP, alkaline phosphatase; CEA, carcinoembryonic antigen; CA19-9, carbohydrate antigen 19-9.
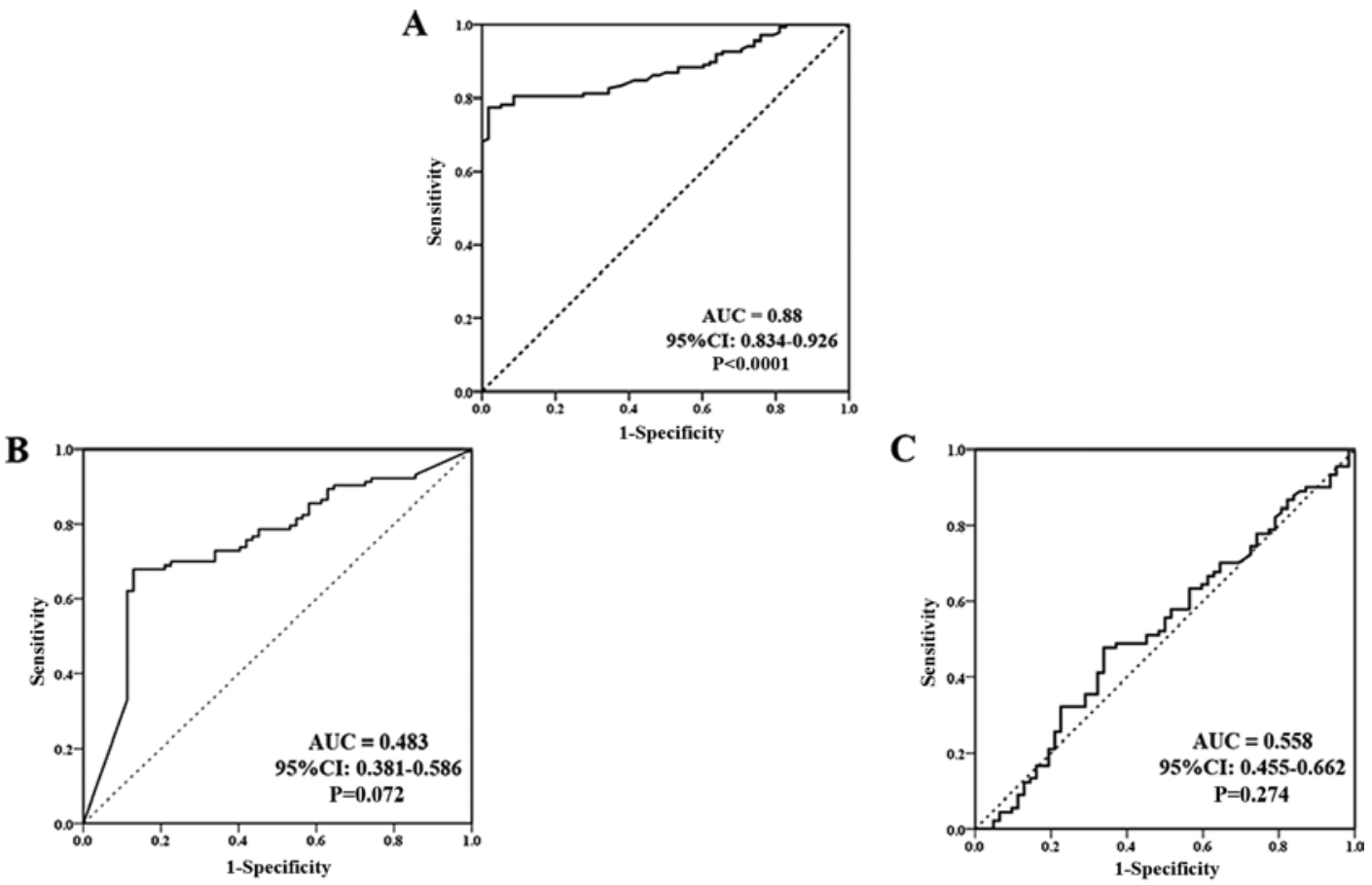

Figure 8. ROC curve evaluation of CCDC25, CA19-9 and CEA serum levels in the BBD and CCA groups. (A) ROC curve of the CCDC25 level in the BBD and CCA groups represented 75\% sensitivity and $84 \%$ specificity, and a cut-off CCDC25 level of $0.18 \mathrm{ng} / \mu \mathrm{l}$ (B) ROC curve of serum CA19-9 level in the BBD and CCA groups represented $52.4 \%$ sensitivity and $46.5 \%$ specificity, and a cut-off CA19-9 level of $105.4 \mathrm{U} / \mathrm{ml}$. (C) ROC curve of serum CEA level in the BBD and CCA groups represented $54.4 \%$ sensitivity and $60 \%$ specificity, and a cut-off CEA level of $19.6 \mathrm{ng} / \mathrm{ml}$. ROC, receiver operating characteristic; CCDC25, coiled-coil domain containing 25; CA19-9, carbohydrate 19-9 antigen; CEA, carcinoembryonic antigen; AUC, area under the curve; CI, confidence interval. 


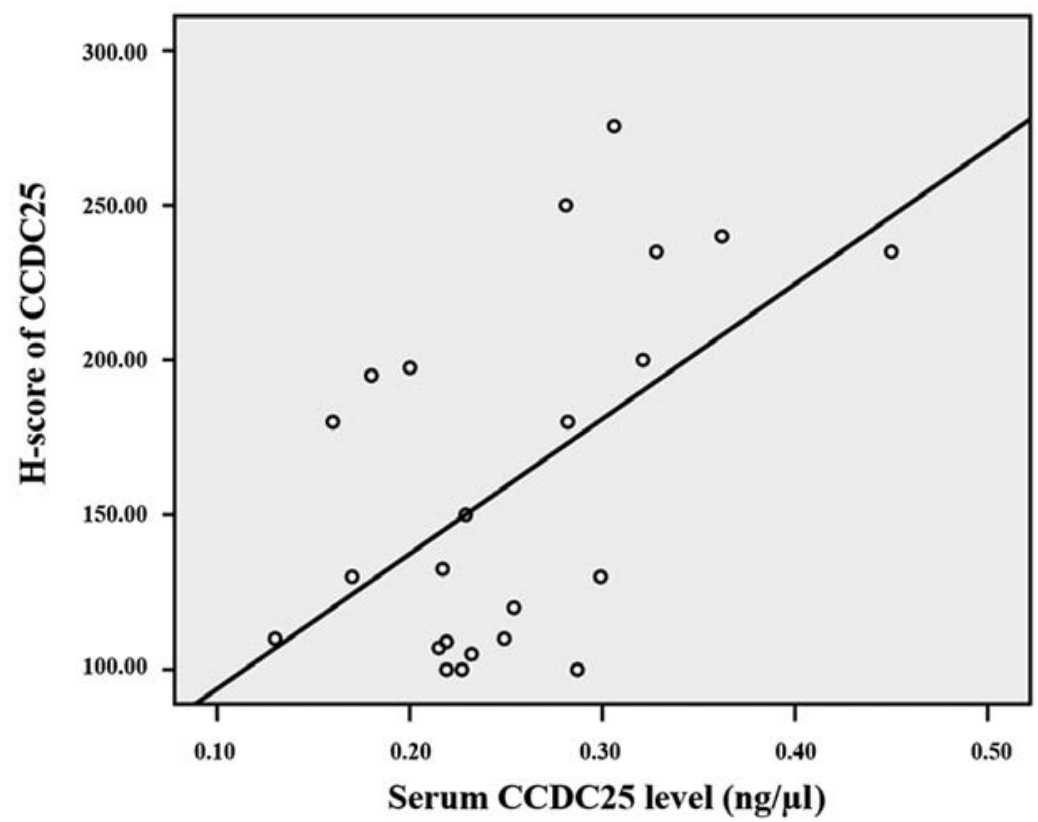

Figure 9. Correlation between the serum CCDC25 level and the CCDC25 H-score. The Spearman's correlation test revealed a moderate positive correlation between the two variables. $\mathrm{r}^{2}=0.52, \mathrm{P}=0.01$. CCDC25, coiled-coil domain containing 25 .

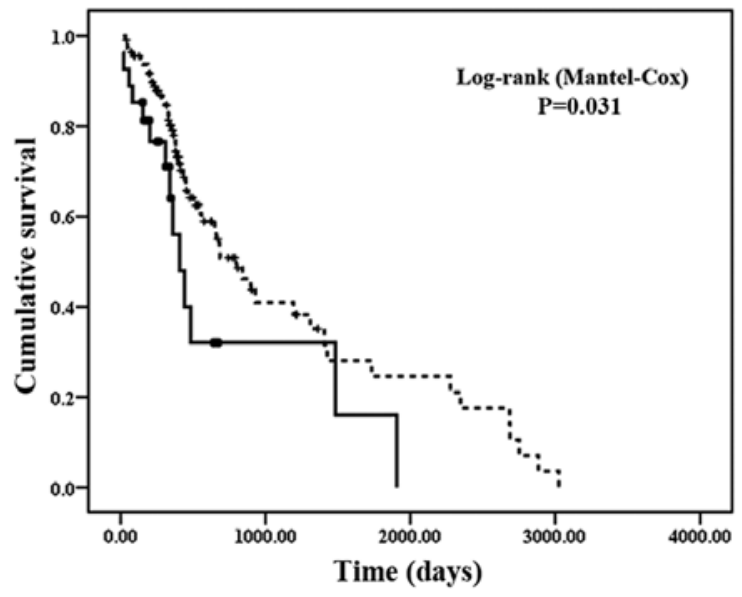

Coiled-coil domain containing 25 (CCDC25)

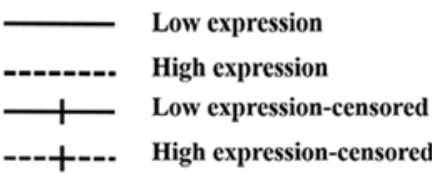

Figure 10. Overall survival time of patients with cholangiocarcinoma with low and high CCDC25 serum levels estimated using the Kaplan-Meier method. The overall survival times was significantly higher in patients with high serum CCDC25 levels compared with those with low levels (365 days vs. 242 days; $\mathrm{P}=0.031$ ). Censored data represent incomplete information for a study participant, observation or value of a measurement.

groups or patients with metastatic and non-metastatic CCA. Dot blot analysis has been widely used in immunodiagnostics, as it saves times, is inexpensive and reduces the number of practical laboratories steps $(23,24)$. Moreover, a multiple dot blot assay is considered to have a similar accuracy to enzyme-linked immunosorbent assay (ELISA) $(23,25,26)$. ELISA kits are not always available for novel biomarkers or uncommon proteins, and previous studies have reported the use of a dot blot assay based on the standard curve to quantitate protein level in serum $(17,18,27)$. Thus, the present study employed a dot blot assay with a standard curve produced by the standard recombinant CCDC25 protein for the quantitative measurement of CCDC25. However, ELISA techniques are still recommended for the accurate measurement of the concentration of CCDC25 in CCA sera; therefore, an ELISA system should be developed for further studies.
In the present study, CCDC25 expression in cancerous tissues, as determined by immunohistochemistry, was correlated with serum CCDC25 level, suggesting that CCA cells are the major source of CCDC25 in the sera. Certain studies have reported that protein levels in serum samples may differ from protein expression levels in tissue due to a modification process during protein translocation $(28,29)$. Therefore, to further validate that serum CCDC25 is mainly derived from CCA tissue, the association of serum and tissue CCDC25 expression levels should be verified using a larger number of paired samples. Furthermore, the quantitative production/release of CCDC25 from CCA cells should be investigated using CCA cell lines to validate the secretory protein nature of CCDC25.

In terms of the diagnostic value of CCDC25 for CCA, ROC analysis revealed a sensitivity and specificity of 93.0 and $100 \%$, respectively, with a cut-off value of $0.11 \mathrm{ng} / \mu 1$. 
Imaging techniques, including ultrasound or computed tomography/MRI in combination with laboratory testing of CA19-9 and CEA, are currently used for the diagnosis of CCA (30). However, in the present study, serum CA19-9 and CEA levels were not as efficient CCA levels, as the sensitivity and specificity of these biomarkers were lower compared with the serum CCDC25 level, and did not differentiate between patients with BBD and CCA. Moreover, the median serum levels of CA19-9 and CEA in the CCA and BBD groups were not significantly different. Additionally, the serum CA19-9 and CEA levels were not significantly correlated with serum CCDC25 level. A low diagnostic value of CA19-9 has also been reported in other studies $(31,32)$. In the current study, serum CCDC25 level could discriminate between BBD and CCA patients more effectively compared with CEA or CA19-9. Therefore, CCDC25 may serve as a biomarker for the differential diagnosis of patients with CCA or BBD. The present study analyzed a relatively homogenous population of patients with stage 3-4 intrahepatic Ov-associated CCA. Nevertheless, the serum CCDC25 level of patients with CCA showed considerable variation. Therefore, it would be of interest to investigate potential correlations between CCDC 25 and anatomical tumor location, histopathological type or tumor stage for further evaluation of the diagnostic value of CCDC25 in CCA.

Numerous protein molecules have been reported to be upregulated in CCA and identified as potential tumor markers $(7,33,34)$. In addition, close associations have been identified between protein molecules and poor prognosis in CCA (7). In the present study, however, Kaplan-Meier analysis revealed that elevated CCDC25 levels in the serum and tissue samples of patients with CCA were associated with longer survival times. Upregulation of human kallikrein-11 is associated with a longer survival time for patients with non-small cell lung cancer (35). In addition, a high BAG cochaperone 1 level is associated with increased survival time for patients with stage I-II breast cancer (36). Furthermore, Caron et al (37) reported that positive caudal type homeobox 2 (CDX2) expression is associated with improved survival times compared with negative CDX2 expression in pancreatic ductal adenocarcinoma. Certain cancerous or immune cells produce/release substances that promote apoptosis, which affects the survival rates of patients with various cancer types, including breast cancer, hepatocellular carcinoma and pancreatic cancer (38). Related to this, CCDC25 has been reported to be a hub gene of hepatocyte nuclear factor $4 \mathrm{a}$, a transcription factor or orphan nuclear receptor, which decreases cancer cell growth in hepatocellular carcinoma $(39,40)$. Furthermore, loss of several genes, including CCDC25 on chromosome $8 \mathrm{p}$, reduces the survival time of patients with hepatocellular carcinoma (41). In the present study, according to bioinformatics analysis, CCDC25 was identified to interact with a number of molecules that serve different roles, including anticancer and cancer promoting roles. As an molecule with anticancerous properties, muscle RAS oncogene homolog has been identified to be upregulated in Emodin-treated hepatoma cells, and Emodin can inhibit the growth of hepatoma cells (42). Moreover, EIF1AY is a Y chromosome gene, and the loss of $\mathrm{Y}$ chromosome in peripheral blood is significantly associated with short survival time and a high risk of developing numerous cancer types, such as liver cancer, melanoma and prostate cancer (43). However, an increase in ESCO1 expression is associated with poor survival time in patients with bladder cancer. Previous studies revealed that lung cancer cell migration was induced by the overexpression of RCC2 $(44,45)$.

In summary, the present study demonstrated that CCDC25 is upregulated in CCA cells and the CCDC25 level in serum may serve as a potential tumor marker for the screening or diagnosis of CCA. However, the role of CCDC25 in the development and progression of CCA remains unclear. Furthermore, the mechanisms regulating $\mathrm{CCDC} 25$ protein expression in CCA cells require further investigation. As CCDC25 was identified as a potential functional protein from the genome database (12-15) and only recombinant protein and antibody against it were produced, the biological and physiological functions of CCDC25 is almost unknown (10). Overexpression by gene transfection or depressed production by gene silencing using CCA cells will elucidate the biological role of CCDC25 and possible regulatory mechanisms of its expression. Moreover, in vivo behavior of the gene-manipulated CCA cells will provide the importance of CCDC25 in tumor progression and/or metastasis. All those possibilities can be investigated further in the future.

\section{Acknowledgements}

The authors would like to thank Professor Yukifumi Nawa (Tropical disease research center, Faculty of Medicine, Khon Kaen University, Thailand) for editing the manuscript and Professor Sopit Wongkham and Associate Professor Chaisiri Wongkham (both Department of Biochemistry, Faculty of Medicine, Khon Kaen University, Khon Kaen, Thailand) for their comments related to study design.

\section{Funding}

The present study was supported by Khon Kean University Grant (grant no. 6200020005). Moreover, this study was supported by the Publication Clinic of the Research Affairs, Khon Kaen University (grant no. PCO-295), the Research Fund for Supporting Lecturer to Admit High Potential Student to Study and Research on His Expert Program 2016, Graduate School, Khon Kaen University.

\section{Availability of data and materials}

The datasets used and/or analyzed during the current study are available from the corresponding author on reasonable request.

\section{Authors' contributions}

Conceptualization of study design was performed by TP, TL, SR, AJu and SP. Data analysis was performed by RC. SP and SR performed the experiments; Methodology was completed by RC, DC, AT, and AJa. RC drafted the original manuscript. $\mathrm{SP}$ and TP reviewed and edited the final manuscript.

\section{Ethics approval and consent to participate}

The present study was approved by the Human Ethics Committee of Khon Kaen University, Thailand (approval 
no. HE611410) and written informed consent was obtained from all participants.

\section{Patient consent for publication}

Not applicable.

\section{Competing interests}

The authors declare that they have no competing interests.

\section{References}

1. Sripa B and Pairojkul C: Cholangiocarcinoma: Lessons from Thailand. Curr Opin Gastroenterol 24: 349-356, 2008.

2. Lozada ME, Chaiteerakij R and Roberts LR: Screening for hepatocellular carcinoma and cholangiocarcinoma: Can biomarkers replace imaging? Curr Hepatol Rep 14: 128-138, 2015.

3. Razumilava N, Gores GJ and Lindor KD: Cancer surveillance in patients with primary sclerosing cholangitis. Hepatology 54 $1842-1852,2011$

4. Ong S, Sachdeva A, Garcea G, Gravante G, Metcalfe M, Lloyd D, Berry D and Dennison A: Elevation of carbohydrate antigen 19.9 in benign hepatobiliary conditions and its correlation with serum bilirubin concentration. Dig Dis Sci 53: 3213-3217, 2008

5. Silsirivanit A, Araki N, Wongkham C, Pairojkul C, Narimatsu Y, Kuwahara K, Narimatsu H, Wongkham S and Sakaguchi N: A novel serum carbohydrate marker on mucin 5AC: Values for diagnostic and prognostic indicators for cholangiocarcinoma Cancer 117: 3393-3403, 2011.

6. Leelawat K, Narong S, Wannaprasert J and Ratanashu-ek T: Prospective study of MMP7 serum levels in the diagnosis of cholangiocarcinoma. World J Gastroenterol 16: 4697-4703, 2010.

7. Wongkham S and Silsirivanit A: State of serum markers for detection of cholangiocarcinoma. Asian Pac J Cancer Prev 13 (Suppl): S17-S27, 2012.

8. Apweiler R, Bairoch A, Wu CH, Barker WC, Boeckmann B, Ferro S, Gasteiger E, Huang H, Lopez R, Magrane M, et al: UniProt: The universal protein knowledgebase. Nucleic Acids Res 32 (Database Issue): D115-D119, 2004.

9. Uhlén M, Fagerberg L, Hallström BM, Lindskog C, Oksvold P, Mardinoglu A, Sivertsson Å, Kampf C, Sjöstedt E, Asplund A, et al: Proteomics: Tissue-based map of the human proteome. Science 347: 1260419, 2015.

10. Proungvitaya S, Klinthong W, Proungvitaya T, Limpaiboon T, Jearanaikoon P, Roytrakul S, Wongkham C, Nimboriboonporn A and Wongkhamand S: High expression of CCDC25 in cholangiocarcinoma tissue samples. Oncol Lett 14: 2566-2572, 2017.

11. Suresh K and Chandrashekara S: Sample size estimation and power analysis for clinical research studies. J Hum Reprod Sci 5 : 7-13, 2012.

12. Almagro Armenteros JJ, Tsirigos KD, Sønderby CK, Petersen TN, Winther O, Brunak S, von Heijne $G$ and Nielsen $H$ : SignalP 5.0 improves signal peptide predictions using deep neural networks. Nat Biotechnol 37: 420-423, 2019.

13. Bendtsen JD, Jensen LJ, Blom N, Von Heilne G and Brunak S: Feature-based prediction of non-classical and leaderless protein secretion. Protein Eng Des Sel 17: 349-356, 2004.

14. Nanjappa V, Thomas JK, Marimuthu A, Muthusamy B, Radhakrishnan A, Sharma R, Ahmad Khan A, Balakrishnan L, Sahasrabuddhe NA, Kumar S, et al: Plasma proteome database as a resource for proteomics research: 2014 update. Nucleic acid Res 42: D959-D965, 2014.

15. Kuhn M, Szklarczyk D, Pletscher-Frankild S, Blicher TH, von Mering C, Jensen LJ and Bork P: STITCH 4: Integration of protein-chemical interactions with user data. Nucleic Acids Res 42 (Database Issue): D401-D407, 2014.

16. Wu L, Huang $\mathrm{P}$, Wang F, Li D, Xie E, Zhang $\mathrm{Y}$ and Pan S: Relationship between serum CA19-9 and CEA levels and prognosis of pancreatic cancer. Ann Transl Med 3: 328, 2015.

17. Taylor SC, Berkelman T, Yadav G and Hammond M: A defined methodology for reliable quantification of western blot data. Mol Biotechnol 55: 217-226, 2013.
18. Fang R, Wey A, Bobbili NK, Leke RFG, Taylor DW and Chen JJ: An analytical approach to reduce between-plate variation in multiplex assays that measure antibodies to plasmodium falciparum antigens. Malar J 16: 287, 2017.

19. Ma HY, Lu YN, Marchbanks PA, Folger SG, Strom BL, McDonald JA, Simon MS, Weiss LK, Malone KE, Burkman RT, et al: Quantitative measures of estrogen receptor expression in relation to breast cancer-specific mortality risk among white women and black women. Breast Cancer Res 15: R90, 2013.

20. Farrah T, Deutsch EW, Omenn GS, Campbell DS, Sun Z, Bletz JA, Mallick P, Katz JE, Malmström J, Ossola R, et al: A high-confidence human plasma proteome reference set with estimated concentrations in PeptideAtlas. Mol Cell Proteomics 10: M110.006353, 2011.

21. Schober P, Boer C and Schwarte LA: Correlation coefficients: Appropriate use and interpretation. Anesth Analg 126: 1763-1768, 2018.

22. Rabouille C: Pathways of unconventional protein secretion. Trends Cell Biol 27: 230-240, 2017.

23. Stone W, Grabias B, Lanke K, Zheng H, Locke E, Diallo D, Birkett A, Morin M, Bousema T and Kumarand S: A comparison of plasmodium falciparum circumsporozoite protein-based slot blot and ELISA immuno-assays for oocyst detection in mosquito homogenates. Malar J 14: 451, 2015.

24. Kamel HH, Saad GA and Sarhan RM: Dot-blot immunoassay of Fasciola gigantica infection using $27 \mathrm{kDa}$ and adult worm regurge antigens in Egyptian patients. Korean J Parasitol 51: 177-182, 2013.

25. Falconar AK and Romero-Vivas CM: A simple, inexpensive, robust and sensitive dot-blot assay for equal detection of the nonstructural-1 glycoprotein of all dengue virus serotypes. Virol J 10: 126, 2013

26. Vera-Cabrera L, Rendon A, Diaz-Rodriguez M, Handzel V and Laszlo A: Dot blot assay for detection of antidiacyltrehalose antibodies in tuberculous patients. Clin Diagn Lab Immunol 6: 686-689, 1999.

27. Tian G, Tang F, Yang C, Zhang W, Bergquist J, Wang B, Mi J and Zhang J: Quantitative dot blot analysis (QDB), a versatile high throughput immunoblot method. Oncotarget 8: 58553-58562, 2017.

28. Abdullah MI, Lee CC, Junit SM, Ng KL and Hashim OH: Tissue and serum samples of patients with papillary thyroid cancer with and without benign background demonstrate different altered expression of proteins. Peer J 4: e2450, 2016.

29. Grzesiak K, Rył A, Baranowska-Bosiacka I, Rotter I, Dołęgowska B, Słojewski M, Sipak-Szmigiel O, Ratajczak W, Lubkowska A, Metryka E, et al: Comparison between selected hormone and protein levels in serum and prostate tissue homogenates in men with benign prostatic hyperplasia and metabolic disorders. Clin Interv Aging 13: 1375-1382, 2018.

30. Edoo MIA, Chutturghoon VK, Wusu-Ansah GK, Zhu H, Zhen TY, Xie HY and Zheng SS: Serum biomarkers AFP, CEA and CA19-9 combined detection for early diagnosis of hepatocellular carcinoma. Iran J Public Health 48: 314-322, 2019.

31. Zeng $\mathrm{X}$ and Tao $\mathrm{H}$ : Diagnostic and prognostic serum marker of cholangiocarcinoma (review). Oncol Lett 9: 3-8, 2015.

32. Loosen SH, Roderburg C, Kauertz KL, Koch A, Vucur M, Schneider AT, Binnebösel M, Ulmer TF, Lurje G, Schoening W, et al: CEA but not CA19-9 is an independent prognostic factor in patients undergoing resection of cholangiocarcinoma. Sci Rep 7: 16975, 2017.

33. Tshering G, Dorji PW, Chaijaroenkul W and Na-Bangchang K: Biomarkers for the diagnosis of cholangiocarcinoma: A systematic review. Am J Trop Med Hyg 98: 1788-1797, 2018.

34. Cuenco J, Wehnert N, Blyuss O, Kazarian A, Whitwell HJ, Menon U, Dawnay A, Manns MP, Pereira SP and Timms JF: Identification of a serum biomarker panel for the differential diagnosis of cholangiocarcinoma and primary sclerosing cholangitis. Oncotarget 9: 17430-17442, 2018.

35. Unal D, Eroglu C, Tasdemir A, Karaman H, Kurtul N, Oguz A, Goksu S and Kaphen B: Is human kallikrein 11 in non-small cell lung cancer treated chemoradiotherapy associated with survival? Cancer Res Treat 48: 98-105, 2016.

36. Turner BC, Krajewski S, Krajewska M, Takayama S, Gumbs AA, Carter D, Rebbeck RT, Haffty BG and Reed JC: BAG-1: A novel biomarker predicting long-term survival in early-stage breast cancer. J Clin Oncol 19: 992-1000, 2001.

37. Caron B, Nair A, Averous G, Nguimpi-Tambou M, Duluc I, Addeo P, Bachellier P, Barnard D, Freund JN and Reimund JM: CDX2 is a biomarker of better prognosis in pancreatic ductal adenocarcinoma (PDA). Gastroenterology 152 (Suppl 1): S275-S276, 2017. 
38. Lowitz BB and Casciata DA: Principles of medical oncology and cancer biology [Internet]. Philadelphia, PA: Lippincott Williams \& Wilkins, 2000. [visited 2018 Sep 10]. Available from:http://www.justmed.eu/files/st/on.

39. Qu Z, Li D, Xu H, Zhang R, Li B, Sun C, Dong W and Zhang Y: CUL4B, NEDD4, and UGT1As involve in the TGF- $\beta$ signaling in hepatocellular carcinoma. Ann Hepatol 15: 568-576, 2016.

40. Walesky C and Apte U: Role of hepatocyte nuclear factor $4 \alpha$ $(\mathrm{HNF} 4 \alpha)$ in cell proliferation and cancer. Gene Expr 16: 101-108, 2015.

41. Roessler S, Long EL, Budhu A, Chen Y, Zhao X, Ji J, Walker R, Jia HL, Ye QH, Qin LX, et al: Integrative genomic identification of genes on $8 \mathrm{p}$ associated with hepatocellular carcinoma progression and patient survival. Gastroenterology 142: 957-966. $\mathrm{e} 12,2012$.

42. Hsu CM, Hsu YA, Tsai Y, Shieh FK, Huang SH, Wan L and Tsai FJ: Emodin inhibits the growth of hepatoma cells: Finding the common anti-cancer pathway using Huh7, Hep3B, and HepG2 cells. Biochem Biophys Res Commun 392: 473-478, 2010.

43. Kido T and Lau YF: Roles of the Y chromosome genes in human cancers. Asian J Androl 17: 373-380, 2015.
44. Zhang S, Li J, Zhou G, Mu D, Yan J, Xing J, Yao Z, Sheng H, $\mathrm{Li} \mathrm{D,} \mathrm{Lv} \mathrm{C,} \mathrm{et} \mathrm{al:} \mathrm{Increased} \mathrm{expression} \mathrm{of} \mathrm{ESCO1} \mathrm{is} \mathrm{correlated}$ with poor patient survival and its role in human bladder cancer. Tumor Biol 37: 5165-5170, 2016.

45. Pang B, Wu N, Guan R, Pang L, Li X, Li S, Tang L, Guo Y, Chen J, Sun D, et al: Overexpression of RCC2 enhances cell motility and promotes tumor metastasis in lung adenocarcinoma by inducing epithelial-mesenchymal transition. Clin Cancer Res 23: 5598-5610, 2017.

(c) (1) (2) This work is licensed under a Creative Commons Attribution-NonCommercial-NoDerivatives 4.0 International (CC BY-NC-ND 4.0) License. 